\title{
Educação diferenciada e trajetórias profissionais femininas
}

Graziela Perosa

Este artigo tem como objetivo examinar os usos e os efeitos da passagem pelo sistema de ensino, focalizando estratégias desenvolvidas por famílias de dirigentes paulistas para controlar a educação escolar de suas filhas, em uma cidade em acelerado processo de urbanização, crescimento demográfico vertiginoso e de industrialização crescente como era São Paulo nas décadas de 1950 e 1960. Minha intenção é problematizar a relação entre formas de escolarização e destino social no quadro de uma discussão sobre a contribuição da escola para a produção e a reprodução de desigualdades sociais.

Como procuro evidenciar, a ordem social, anterior à instituição escolar, impõe-se sobre o universo escolar, segmentando-o por classe social e, pelo menos até meados dos anos de 1970, por gênero. Essa segmentação interna, como mostra Fritz Ringer (1979), é substantivada pela associação entre tipos de currículos e grupos sociais e se expressa pelas diferenças que podem ser notadas entre as escolas dirigidas para os grupos populares e as escolas para as elites dirigentes, assim como as escolas voltadas para os meninos e as voltadas para as meninas no período examinado. Portanto, pesquisar a relação entre educação e desigualdade social no Brasil implica em pensar o sistema de ensino brasileiro como um espaço desigual. No caso em estudo, será examinado o subespaço específico das escolas privadas católicas voltadas para a clientela feminina. 
1. Sobre a reação das instâncias decisórias na Igreja Católica a essas iniciativas, ver Miceli (1988, pp. 11-59) .

2. Para a autora, esse período de intensas modificações sociais provocou uma reativação da ideologia da essência feminina e do mito do eterno feminino. Cf. Muel Dreyfus (1996, p. 10).

3. Entre 1920 e 1950, a cidade de São Paulo passou de pouco mais de 500 mil para 2 milhôes de habitantes, tornando-se a maior cidade brasileira. Cf. Morse (1970).
O interesse em focalizar esse espaço está relacionado com o prestígio da escola católica na formação das elites brasileiras, especialmente a partir da segunda metade do século XIX, quando diversas ordens religiosas aportaram no Brasil, como resultado da institucionalização da escola republicana na Europa e do conseqüente fechamento das escolas confessionais na maioria dos países europeus ocidentais ${ }^{1}$. A Igreja Católica, principal espaço de circulação social para as mulheres no século XIX, investiu fortemente na manutenção do controle sobre a formação da juventude brasileira e, particularmente, na monopolização da formação escolar feminina, num momento em que estava em jogo reafirmar a "natureza feminina" e sublinhar o lugar certo para as mulheres. Essa atuação se fazia notar na abertura de escolas privadas, de conventos, de universidades católicas, de movimentos de organização dos grupos populares e estudantis, entre outras ações (cf. Miceli, 1988). Tal engajamento pode ser compreendido se considerarmos que a educação feminina era estratégica na conservação dos valores tradicionais da família e do papel da mulher no seu interior, como bem mostrou Francine Muel Dreyfus, para o caso da França da década de $1940^{2}$. A escola católica representava nesse momento uma excelente solução para as famílias do patronato paulista interessadas em garantir instrução às meninas com forte acento moral. Para essas famílias, a escola católica feminina funcionava também como uma estratégia de duplo evitamento. De um lado, impedia-se o contato das meninas com crianças e jovens de outros grupos sociais, em um momento da história da cidade marcado pela explosão demográfica ${ }^{3}$ e, de outro, evitava-se que as moças assumissem o controle sobre suas relaçôes com rapazes de seu próprio grupo.

A interrogação que conduziu este trabalho diz respeito aos efeitos que as formas de socialização em famílias socialmente privilegiadas e em escolas confessionais femininas teria produzido sobre a trajetória individual de mulheres a ela submetida. Para isso, focalizou-se 82 mulheres, brancas, nascidas entre 1938 e 1942 e que concluíram o ensino médio por volta de 1960, em um período de expansão do acesso feminino ao ensino superior brasileiro (cf. Barroso e Mello, 1979).

Ao reunir sistematicamente dados sobre a experiência familiar e escolar do grupo pesquisado, procurei identificar os efeitos concretos, e passíveis de serem pesquisados sociologicamente, da experiência educacional sobre suas trajetórias socioprofissionais. Isso significou tentar registrar dados sobre a experiência social dessas mulheres, em geral percebidas como absolutamente pessoais e privadas, não fossem elas recorrentemente identificadas em um 
conjunto maior de alunos submetidos aos mesmos dispositivos pedagógicos de produção, de comunicação e de avaliação, responsáveis pela formação de estruturas cognitivas que permitem aos indivíduos perceber e julgar o mundo à sua volta (cf. Bourdieu, 2000, p. 3). A pesquisa empírica foi realizada entre 2001 e 2004, e incluiu a reconstituição de endereços e telefones de uma centena de mulheres que foram alunas de três colégios de freiras voltados para atender as famílias da elite dirigente paulista por volta do ano de 1960. Após a consulta às fichas de matrículas das escolas pesquisadas, de documentos escolares e das congregaçóes religiosas, foram enviados, pelo correio, 82 questionários para ex-alunas das três escolas, nos quais se solicitava um retorno reflexivo sobre suas experiências educativas e descrições das características sociais de suas famílias e de seus percursos após a escola ${ }^{4}$. Depois disso, submeti os resultados desses questionários a uma análise fatorial ${ }^{5}$ e escolhi com base em seus resultados as que seriam entrevistadas (quinze mulheres). Além disso, a pesquisa incluiu a observação direta dos espaços escolares, entrevistas com ex-professoras, diretoras e religiosas (treze entrevistas), e o exame de fotografias do ambiente escolar e de jornais e publicações internas desses estabelecimentos de ensino.

As moças que focalizamos neste trabalho participam de uma geração que foi confrontada com a possibilidade concreta de ultrapassar o nível de escolarização de suas mães graças à progressão dos investimentos femininos nos caminhos da escolarização e, em particular, do ingresso feminino no ensino superior brasileiro, que aumentou durante todo o século XX, acentuandose a partir de $1960^{6}$. Uma primeira hipótese explorada é de que o ingresso feminino significativo no ensino superior brasileiro, nesse período, modificou os horizontes possíveis para essa geração de mulheres e em alguns casos, alterou os critérios empregados na escolha dos cônjuges (Cf. Trigo, 1997). A segunda hipótese é a de que haveria um engajamento feminino variável na vida profissional, tributário não só de seu pertencimento a um grupo social e das relaçōes entre homens e mulheres em seu interior, mas também ligado ao tipo de experiência escolar que tiveram.

Procuro, assim, ultrapassar as descrições da posição dominada da mulher no mundo do trabalho como resultado apenas das deficiências do mercado e da estrutura ocupacional ${ }^{7}$ e contribuir com o aprofundamento da compreensão da participação da educação sobre os processos de emancipação feminina. Busco, simultaneamente, lançar luz sobre a posição dos agentes na estrutura social e apreender as reações individuais nesse pequeno grupo de mulheres socialmente situadas, confrontadas com a possibilidade (vir-
4. Por esse meio foi possível reunir 24 questionários de egressas da Escola 1, cujo número total de alunas na época foi estimado em 400 meninas por religiosas entrevistadas; 32 questionários da Escola 2 que, à época, atingira 1.231 alunos; 26 questionários da Escola 3, à época uma escola com apenas 122 alunos. Para informações detalhadas, consultar Perosa (2005).

5. Esse diagrama é produto de uma análise fatorial decorrespondência, realizado a partir dos dados obtidos com os questionários por intermédio do software SAS. Agradeço sua realização a Salah Bouedjaeas discussões estimulantes com Letícia Canêdo, Afrânio Garcia, à Monique de Saint Martin, Jean Pierre FaguereFrançoisBonvin durante meu estágio na École des Hautes Études em Sciences Sociales de Paris.

6. Entre 1956 e 1971, as moças deixaram de representar 26\% dos alunos inscritos no ensino superior brasileiro para chegar a $40 \%$ do total de matriculados. Cf. Barroso e Mello (1977, p. 48). Consul- 
tar também Pastore (1972).

7.Entre eles, na literatura nacional, destacam-se Safiotti, 1981; Aguiar, 1979. Cf. Heilborn e Sorj (1999). tual) de alcançar uma autonomia financeira total ou relativa em relação ao sexo masculino em seu grupo social (pais, irmãos e cônjuges).

A relação feminina com o mundo do trabalho foi bastante estudada no contexto nacional (cf. Heilborn e Sorj, 1999). Nesses estudos, toma-se como ponto de partida que a educação recebida é um fator decisivo para compreender como a reprodução das desigualdades entre os sexos pode persistir, se reproduzir e/ou se alterar. Tais estudos convergem no sentido de atribuir à "educação para a submissão" a incorporação de uma suposta inferioridade feminina em relação aos homens, o que teria dirigido, por exemplo, a escolha do curso superior na geração que ingressou na universidade por volta de 1960 (cf. Barroso e Mello, 1977; Bruschini, 1978). Busco demonstrar com esta pesquisa como a educação efetivamente contribuiu para a incorporação de disposiçôes femininas diferenciadas, seja por meio das famílias, seja pelo tipo de socialização escolar a que estiveram expostas. Exploro, ainda, a maneira como a escola católica contribuiu para que se desenvolvesse uma cumplicidade razoável (e variável) com uma predestinação sexual, essencialmente ligada às diferenças anatômicas entre homens e mulheres. $\mathrm{O}$ interesse em expor $\mathrm{o}$ material empírico reunido reside em poder descrever e analisar os processos por meio dos quais a posição - de classe e de gênero - em uma determinada estrutura e em uma dada configuração social se transforma em filtros pelos quais os indivíduos percebem e julgam o que é possível ou impossível para si mesmo, o que teria resultado em investimentos diferenciados por parte desse grupo de mulheres em uma ou outra esfera da vida social.

A idéia de que os primeiros anos de vida de um indivíduo são de importância decisiva sobre seu modo de perceber o mundo e de se relacionar com ele integra às representações do senso comum sobre a importância da educação e boa parte dos estudos sociológicos sobre o processo de socialização (cf. Durkheim, 1922; Elias, 2000; Berger e Luckmann, 1994; Bourdieu, 1980). Há concordância sobre o fato de que os indivíduos são construídos socialmente, "produzidos" pela sociedade na qual estão inseridos. O desafio desta pesquisa foi demonstrar como e por meio de quais mecanismos eles incorporam a sociedade em que vivem e quais são os efeitos concretos dos processos de socialização sobre trajetórias individuais. $\mathrm{Na}$ formulação bourdieusiana, tratar-se-ia de um processo infindável de incorporação das estruturas sociais e de sua transformação em esquemas de percepção, categorias de julgamento que orientam a ação (cf. Bourdieu, 1980, p. 96). Violência simbólica que resultaria na imposição de uma dada representação do mundo social, hierarquizada por classe e gênero, que prefiguram e circunscre- 
vem os futuros possíveis e/ou impossíveis para cada um. O resultado seria a constituição de disposições permanentes nos indivíduos (habitus), materializadas na forma de se apresentar, de falar, de sentir e de pensar (Idem, p. 117). Em que pese os efeitos dessa violência simbólica operada pela educação, essa pesquisa pretende contribuir para pensar como tais disposições interagiram com algumas modificações de um dado período histórico, marcado pelo fortalecimento do feminismo, pelo ingresso maciço das mulheres no ensino superior, pela entrada em novas posições no mercado de trabalho e pelo desenvolvimento de novas aspirações femininas no que tange ao mundo social.

\section{Socializações}

Por volta de 1950, o espaço da "boa educação" para meninas diversificara-se, expressando variações na elaboração do feminino, atendendo às expectativas educacionais das famílias que se diferenciavam entre si. Visando a observar de perto essas alteraçōes analisei as características da socialização em três colégios femininos. Busquei compreender por que tais escolas recebiam fraçōes distintas do patronato paulista e, por fim, interrogar se essas socializações teriam produzido efeitos sobre suas trajetórias ulteriores. Esses efeitos foram pesquisados a partir de uma "genealogia comparada" dos grupos familiares e da socialização escolar a que essas alunas estiveram expostas até o ensino secundário.

As famílias que buscavam os colégios compunham parte da elite dirigente paulista e, em menor número, das classes médias. Eram chefiadas por grandes proprietários rurais e urbanos (fazendeiros, industriais, grandes atacadistas do comércio), profissionais liberais (médicos, advogados, engenheiros) e por pequenos comerciantes bem-sucedidos. Mesmo que o público de cada uma das escolas não seja tão homogêneo como se quer crer, os dados produzidos sugerem que elas atendiam a fraçōes bem delimitadas no interior desse grupo social. À Escola 1 cabia a fração mais antiga e bem estabelecida da elite agrária paulista, com claro predomínio de famílias da segunda geração de proprietários rurais, bem como de diploma de ensino superior. As irmãs do colégio eram muitas vezes ex-alunas e/ou filhas de ex-alunas e possuíam formação no ensino superior, por vezes obtidas em universidades católicas da Europa. A Escola 2 recebia uma clientela mais heterogênea, composta de famílias que possuíam um capital econômico mais recente e menos variado, pais na primeira geração de proprietários ru- 
rais e na primeira geração com ensino superior. Vindas de famílias de pequenos agricultores italianos, as noviças marcelinas possuíam uma origem social mais modesta e provinciana do que as das outras congregações (cf. Marchetti e Polinésio, 1999). A Escola 3 recebia uma fração relativamente mais urbana e mais nova dos grupos dominantes, na segunda geração de profissionais liberais, com uma história de ascensão social mais ligada à posse de elevado capital cultural, apresentando menor patrimônio rural ou urbano na geração dos avós. As irmãs à frente do colégio eram norte-americanas, se destacavam das demais por possuírem uma experiência internacional baseada em missões na África e na Índia e por práticas raras entre as religiosas do período no Brasil, como nadar e dirigir carros.

Características da Experiência Escolar, 1960

\begin{tabular}{|c|c|c|c|}
\hline & Escola 1 & Escola 2 & Escola 3 \\
\hline $\begin{array}{l}\text { DATA DE FUNDAÇĀO DO } \\
\text { COLÉGIO NO BRASIL }\end{array}$ & 1907 & 1927 & 1947 \\
\hline Programa de ENSINO & $\begin{array}{l}\text { Clássico (experimental } \\
\text { durante um período). }\end{array}$ & Clássico. & $\begin{array}{l}\text { Experimental } \\
\text { (mais flexível). }\end{array}$ \\
\hline CÓdigo DISCIPLINAR & $\begin{array}{l}\text { Controle mais "suave" do compor- } \\
\text { tamento, premiaçōes e sançôes } \\
\text { clássicas,maior continuidade entre } \\
\text { o ambiente familiar e escolar. }\end{array}$ & $\begin{array}{l}\text { Austera,punições e castigos fre- } \\
\text { qüentes, delação, exposição } \\
\text { pública dos "erros". }\end{array}$ & $\begin{array}{l}\text { "Moderno", ambiente menos } \\
\text { escolar, delação. }\end{array}$ \\
\hline UMA AULA DE HISTÓRIA & $\begin{array}{l}\text { "Linha do tempo": propunha-se } \\
\text { que as alunas relacionassem acon- } \\
\text { tecimentos da história brasileira ao } \\
\text { nascimento de seus antepassados } \\
\text { familiares. }\end{array}$ & $\begin{array}{l}\text { Elaboradas a partir de datas } \\
\text { cívicas. As meninas eram desen- } \\
\text { corajadas a interromper a aula } \\
\text { com perguntas. Desenho e apre- } \\
\text { sentação dos acontecimentos } \\
\text { ć́vicos à turma. }\end{array}$ & $\begin{array}{l}\text { A professora possuía autonomia } \\
\text { para modificar o programa, } \\
\text { quando julgasse importante a } \\
\text { introdução de conteúdos ("por } \\
\text { exemplo, a China", relatou a } \\
\text { professora de história entrevistada) }\end{array}$ \\
\hline HORA DO ALMOÇO & $\begin{array}{l}\text { Ritualizado, os talheres eram tra- } \\
\text { zidos de casa com o nome de famí- } \\
\text { lia gravado. Lugares fixos.Contro- } \\
\text { le das etiquetas interno ao grupo: } \\
\text { "pegaria mal você comer feio" e } \\
\text { "alguém nos servia" disse uma } \\
\text { ex-aluna. }\end{array}$ & $\begin{array}{l}\text { As irmãs acompanhavam a } \\
\text { refeição das meninas corrigindo } \\
\text { a aquisição da etiqueta, tocando } \\
\text { com uma vara as costas daquelas } \\
\text { que não se mantivessem eretas. }\end{array}$ & $\begin{array}{l}\text { A cada dia uma aluna era responsá- } \\
\text { vel por apresentar um assunto "ame- } \\
\text { no" durante as refeiçōes; eram res- } \\
\text { ponsáveis pela louça e por servir-se } \\
\text { à mesa.A aquisição da habilidade de } \\
\text { se responsabilizar perante o grupo. }\end{array}$ \\
\hline
\end{tabular}

A pesquisa revelou também que, graças à existência de uma sólida rede de escolas privadas, era possível construir um fino ajustamento entre as características sociais das famílias e das escolas, ao gosto do freguês: "mais austera", "mais moderna", ou nem austera nem moderna, simplesmente "clássica". Com isso a presença da escola privada reifica a diferenciação interna do sistema de ensino pela clivagem social. Agrupando e segregando 
os alunos pela origem, programa escolar e destino social, garante às famílias de mais alta renda no Brasil a possibilidade de controlar e proteger a educação das crianças de uma forma muito mais eficaz do que é possível aos outros grupos sociais ${ }^{8}$.

No entanto, importa perguntar: teria feito de fato alguma diferença estudar em uma ou em outra escola? Ter um pai grande proprietário rural ou profissional liberal autônomo? Para responder a essas perguntas, extraí do material empírico os dados sobre a origem social, a escola, os padrões de casamentos, o número de filhos e os modos de profissionalização observados a posteriori. Variáveis pertinentes para examinar nossas hipóteses iniciais, o que foi feito a partir do resultado da submissão dos dados a uma análise fatorial. Esse procedimento metodológico permite uma visualização quase "geográfica" das distâncias e das proximidades dos percursos, favorecendo a apreensão simultânea e de forma relacionada da posição dos indivíduos na estrutura social e de algumas tomadas de posição decisivas para o curso de suas trajetórias (cf. Bourdieu, 1989; Lebaron, 1998). Sem a pretensão de esgotá-los, a apresentação de casos "exemplares" busca retratar os dilemas a que todas elas estiveram expostas e a maneira como elas reagiram a eles?.

Partiu-se do princípio de que cada um deve ao tipo de aprendizagem social que recebeu (familiar e escolar, especialmente) um conjunto de esquemas de pensamento, habitus incorporados, que servem de base para a aquisição de esquemas ulteriores, organizando-os, definindo sentidos "possíveis" e sentidos "proibidos", constitutivos do pensamento e fortemente inculcados pela posição em um universo social e de maneira explícita pela instituição escolar (cf. Bourdieu, 1999). Transformados em automatismos intelectuais de base, esse impensado da educação, espécie de inconsciente da escola (cf. Bourdieu, 2000, p. 4) orientou as "escolhas" e os investimentos inaugurais em momentos decisivos, como o final do secundário, o ingresso no ensino superior, os casamentos etc. Um tema recorrente a esse grupo era não por acaso a relação entre o casamento e o trabalho feminino, debate antigo e caro ao movimento feminista (cf. Scott, 1990; Thébaud, 2001, p. 29).

Por meio do Diagrama a seguir, nota-se a tripla determinação dessas trajetórias socioprofissionais, visualizando-se os fatores ligados à origem social, aqueles relacionados com a experiência de escolarização e as carreiras masculinas de seus maridos. O eixo vertical opõe as famílias que possuíam maior capital econômico e cultural àquelas com menor recursos em relação às demais. $\mathrm{O}$ eixo horizontal distingue, à esquerda, as que seguiram uma
8. A continuidade entre a educação familiar e escolar tende a tornar essa experiência ainda mais coesa e eficaz em seus objetivos, provocando efeitos ainda mais duradouros no que diz respeito à formação do habitus (cf. Saint-Martin, 1990).

9. Os "casos" apresentadosaqui, com nomesfictícios, correspondem às trajetóriascom maiorincidência entre as egressas pesquisadas de cada escola. Houve variabilidade no interior de cada escola euma análise detida permite explorar os "contra exemplos", combatendo os riscos da estereotipia. A esse respeito, consultar Perosa (2005). 
atividade profissional, daquelas que abandonaram-na precocemente, ou nem chegaram a iniciá-la, situação mais freqüente entre as egressas da Escola 1 e da Escola 2 e com menor incidência entre as ex-alunas da Escola 3.

\section{DiAgrama}

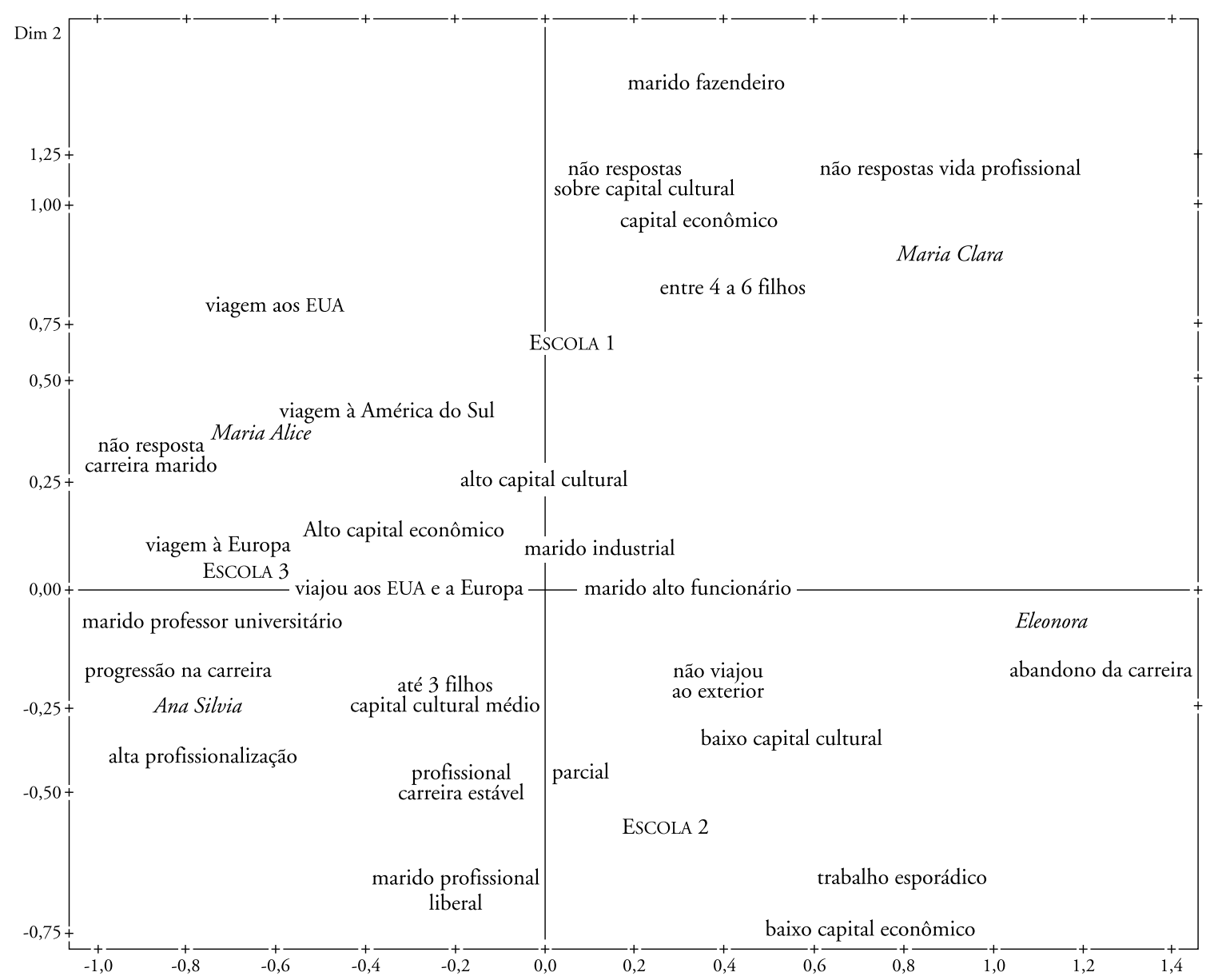

No quadrante superior direito, ficaram aquelas que, como Maria Clara, têm alto capital econômico, casaram-se no interior do seu grupo social e não chegaram a desempenhar uma atividade profissional. Casadas com industriais, grandes comerciantes e fazendeiros, "esposas e colaboradoras" das carreiras masculinas (cf. Faguer, 1997a), dedicaram-se à maternidade e tiveram um maior número de filhos. A tripla determinação de suas trajetórias tornou-se ainda mais clara quando comparadas àquelas localizadas à esquerda do eixo vertical, casos de Maria Alice e Ana Silvia. Elas tiveram um 
número menor de filhos, casaram-se com profissionais liberais em sua maioria. A análise da variação dessas tomadas de posição expressa formas diferenciadas de fazer o investimento inaugural, delineado ao final da adolescência e implicado nos jogos sérios ${ }^{10}$ de que é feito o mundo social. Para o grupo em questão, isso esteve relacionado com as atitudes em face do ingresso ou não no ensino superior e no mundo do trabalho, e da dedicação, exclusiva ou não, ao casamento e à maternidade. Neste momento de encruzilhada, as decisões tomadas expressam apostas heterogêneas em modelos e ideais do feminino que estavam em recomposição. Pelo exame dessas tomadas de posição ante esse "tema comum", lugar de encontro das preocupações do grupo, reconhecem-se os efeitos da ordem mítica à qual estavam expostas nas escolas católicas.

As moças das três escolas ingressaram no ensino superior, predominantemente em universidades católicas. De novo, os efeitos de uma elaboração de um feminino mais conquistador e menos submisso, da Escola 3, parece ter feito diferença, já que elas foram em maior número para as universidades públicas - espaços mistos de educação, sacudidos nesse período da história do país, por um movimento de contestação estudantil, materializado, a partir de 1964, na resistência à ditadura militar e a tudo que ela representava na forma de conceber as relações sociais e políticas no país. Ingressar na Universidade de São Paulo significava adentrar um espaço público, misto, fora do controle moral imposto pela religião e pelas famílias, no qual as meninas estariam expostas à influência de um ambiente intelectual laico e à convivência com jovens de origem social mais heterogênea. Nisso elas foram seguidas pelas meninas da Escola 2, e, por último, da Escola 1. A aquisição dos diplomas superiores deu-se predominantemente nos cursos voltados para receber a clientela feminina, tais como letras, pedagogia, psicologia, história, serviço social e belas-artes, acompanhando as estatísticas nacionais ${ }^{11}$. Tais diplomas possuem em comum o fato de conduzirem para o exercício do magistério e por erigirem as disposições associadas ao "feminino" em qualidades profissionais. Entre as meninas vindas da escola na qual a submissão era um valor exaltado, como era o caso da Escola $2^{12}$, predominou uma escolha profissional que dava acesso ao magistério primário e secundário. Já para as ex-alunas da Escola 3, os cursos superiores deram acesso ao magistério no ensino superior, posição simbólica e materialmente dominante se comparada ao magistério de ensino primário e secundário. A militância histórica da Igreja Católica na elaboração de uma doutrina que fazia do casamento uma especialidade da teologia católica romana - cujos "cursos
10. Cf. Bourdieu, 1996, p. 27.

11.Em 1971 metade do contingente feminino no ensino superior brasileiro estava inscrita nos cursos de letras, pedagogia, história, geografia, ciências sociais e psicologia, habilitações que possuíam em comum o fato de que conduziam as mulheres ao exercício do magistério. Nos cursos tradicionalmente masculinos, tais como o direito, engenharia e medicina, o percentual feminino no mesmo período era de $11 \%, 6 \%$ e $4 \%$, respectivamente. Cf. Barroso e Mello, 1977.

12. "Je suis modèste et sousmise" era um exercício de cópia presente na aula de francês de uma egressa da Escola 2 nos anos de 1930. 
13. Proporção bastante superior à taxa de mulheres casadas no Brasil. Em 1950 essa taxa era de 54,1\%; em 1960, 53,4\%; em 1970, 50,6\%; em 1980, 49,5\%; em 1991, caiupara 46,7\% (cf. Freire et al., 2005, p. 4).

14. Como se sabe, a taxa de mulheres separadas e/ou divorciadas cresceu ao longo das décadas no Brasil. Em 1950 , apenas $0,2 \%$ das brasileiras estavam nessa condição, em 1960 elas já eram 3,2\%, em 1970 somavam 3,4\%, taxa mantida em 1980 e que chega a $6 \%$ em 1991 (apud Barroso e Mello, 1977). de noivos" são apenas uma expressão - se fez sentir nesse grupo, uma vez que o celibato foi uma condição excepcional, sendo o caso de apenas três num conjunto de $82^{13}$. Em relação ao divórcio, regulamentado no país apenas em 1977, as egressas da Escola 2 separaram-se proporcionalmente menos (seis sobre 32), seguidas das ex-alunas da Escola 1 (cinco sobre 24) e, em número bastante superior, pela ex-alunas da Escola 3 (onze sobre 26) ${ }^{14}$. A "grande mãe" de família numerosa foi uma condição minoritária nas três escolas, mas o número delas foi três vezes maior entre as egressas da Escola 1 - escola católica austera, centrada no castigo dos pecados, na qual o feminino deveria estar à disposição da "natureza" procriadora e a contracepção era considerada uma rebeldia. A exposição de algumas trajetórias individuais pretende contribuir para elucidar a dimensão inseparavelmente social e psíquica da incorporação do mundo social.

\section{Eleonora}

Eleonora é neta de imigrantes europeus. Seu avô paterno tinha origem espanhola e comercializava louças. $\mathrm{O}$ avô materno viera da Itália já engenheiro para trabalhar como profissional liberal, ganhando a vida no agitado mercado da construção civil da cidade. Seu pai nascera na capital, estudara em um ginásio estadual e formara-se na Escola Politécnica de São Paulo, profissão que seguiu durante toda sua vida e que lhe garantiu uma trajetória de ascensão social. Italiana e ex-aluna da Escola 2, sua mãe estudara química na Universidade de São Paulo, mas seu diploma não chegou a ser utilizado para uma profissionalização e cumpria apenas uma função de valorização pessoal. Aluna desde a primeira série primária até formar-se no curso científico na Escola 2, sua trajetória oferece a possibilidade de examinar a lógica da interrupção da tentativa de "trabalhar fora". Ela me recebeu para a entrevista em seu amplo sobrado localizado na zona oeste de São Paulo. Apesar das empregadas uniformizadas que vieram nos servir, Eleonora me recebeu pessoalmente na porta. Os vários ambientes do andar térreo da casa davam vista para uma piscina, em volta da qual seus dois netos e a babá brincavam. Eleonora me explicou logo que fazia tudo para que sua filha não abandonasse a carreira.

Nascida em uma família católica e conservadora, a educação das crianças era claramente diferenciada por sexo. As duas meninas foram para a escola católica e os três meninos para um estabelecimento privado e laico, ingressando mais tarde na Universidade de São Paulo. "Eu tenho a impres- 
são de que teria sido diferente se eu estudasse no Rio Branco... eu teria entrado numa USP”. Eleonora era uma boa aluna de matemática, um conhecimento altamente valorizado pelo pai engenheiro politécnico, mas sofrera para se alfabetizar e atribuiu seu baixo desempenho na escola à sua "distração". Apesar deste diagnóstico precoce desestimulante, Eleonora prosseguiu seus estudos secundários no curso científico e fez matemática no Sedes Sapientae. A essa altura, entretanto, Eleonora já namorava seu vizinho, compromisso assumido aos 15 anos de idade, sob a vigilância atenta do pai, que impediu o casamento antes da conclusão do ensino superior. $\mathrm{O}$ rapaz era o que se chamava de "bom partido": filho de uma família antiga e bem estabelecida na cidade, era ex-aluno de um prestigiado colégio católico masculino e egresso da Faculdade de Direito do Largo de São Francisco. Para esta menina um pouco estigmatizada na escola pela dificuldade na aprendizagem da leitura, um homem com essas qualificaçōes funcionava como uma autêntica prova de seu valor como mulher, "eu resgatei esse lado da mulher, que acho importante e que eu não tinha...”. Um ano antes de se formar ela começou a trabalhar à noite como professora em uma escola estadual. Formada e casada, alcançara o ideal de muitas meninas de seu grupo social. Após três anos de magistério no ensino público foi convidada por seu professor de estatística da faculdade católica para ajudá-lo a criar um departamento em uma universidade pública recém-instalada no interior paulista. Mas encontrou forte oposição por parte da família do marido. "Que absurdo! Pra quê?", teria dito a sogra "quatrocentona". A proposta era interessante e ela foi duas vezes até lá conferir a possibilidade de trabalho, mas a pressão da sogra, aliada à sua formação católica educacional e familiar, a fez desistir da idéia, imaginando que tudo seria "muito complicado" ${ }^{15}$. A gota d'água para o abandono do magistério teria sido o comentário de uma prima que a vira almoçando com o professor no campus da universidade, atiçando o antigo fantasma do adultério, "aí eu falei: encerra isso". O medo do castigo e a educação austera católica, na qual o marido e o casamento são os deveres femininos por excelência, a fizeram interromper sua curta experiência de trabalho. "Fui caminhando dentro das expectativas", como me disse, e assumiu definitivamente o dever feminino no seu grupo social, acompanhando o marido nas mudanças relacionadas com o trabalho para o exterior, desenvolvendo trabalhos filantrópicos, cuidando de suas duas meninas e assumindo a dianteira no pesado trabalho da administração de sucessivos dramas familiares. Em contraposição às mais profissionalizadas, as não profissionalizadas revelam os limites de um uni-
15. Em correspondência a Romain Rolland, Freud descreveu sua angústia ligada ao mal-estar que pode acometer alguém quando diante do jamais imaginado, do "impossível". Uma mudança de rota na viagem que fizera com o irmão à Itália, na qual foram incentivados a ir para a Grécia, provocou uma melancolia nos irmãos, mais tarde analisada por Freud. "Vamos ver Atenas? Impossível! Vai ser difícil demais!' A depressão concomitante correspondia a um lamento de que era impossível: teria sido tão lindo" (Freud, 2006, p. 239). 
verso de possibilidades em que a vida doméstica, a dedicação à família e o apoio à carreira do marido delimitaram os horizontes. Sem projeto profissional claro, elas dependiam inteiramente de suas alianças matrimoniais. Quando se viram casadas com maridos cujas carreiras eram ascendentes, elas se confrontaram com a obrigação de acompanhar as mudanças (de cidade/país) decorrentes das carreiras masculinas e de interromper projetos profissionais, mais ou menos imaginados ou projetados.

\section{Maria Alice}

Ex-aluna e filha de ex-aluna da Escola 1, ela foi socializada no interior das fraçôes mais bem estabelecidas dos grupos dirigentes no Brasil, que agregavam ao seu patrimônio capital social, cultural e simbólico. Uma de suas lembranças de menina foi sua visita ao Monumento das Bandeiras, então em construção, como parte das comemoraçōes do IV Centenário de São Paulo, acompanhada de seu pai, secretário de Estado, e de Victor Bre-

16.Cf. Arruda (2001). cheret, para verificar o andamento da $\mathrm{obra}^{16}$. Maria Alice recebeu-me para a entrevista em sua casa térrea localizada no Jardim Europa. Uma empregada doméstica, vestida num uniforme azul marinho e branco, conduziu-me por um corredor lateral que dava acesso à edícula da casa, transformada em escritório de Maria Alice. "Eu não era gênio, eu estudava”, apresentou-se. Ainda menina obteve medalha de ouro em conhecimentos escolares em uma competição estadual, cuja entrega dos prêmios foi realizada no Teatro Municipal. Querida pelas freiras e decidida a "ser independente", dona de um bom gosto cultivado, Maria Alice desenvolveu precocemente uma "agenda" de clientes de decoração, tendo começado aos 15 anos com quartos infantis de amigos da família. Ao final do secundário, Alice já estava de casamento marcado. Assim, decidiu ir para o Instituto de Artes e Decoração de São Paulo para fazer "decoração e design". Esta escolha significava uma opção de certa maneira mais modesta e menos ousada se considerarmos seus rendimentos escolares; razão pela qual ela não tentou ingressar em Arquitetura na USP, "eu teria entrado", disse-me com segurança. A consagração escolar precoce e o acúmulo de diversos capitais permitem compreender o uso feito por ela da escola, trabalhando mais sobre o capital social acumulado ali. Pouco disposta ao distanciamento do universo simbólico da família, Maria Alice dedicou-se ao curso de decoração e design, e investiu na preparação da cerimônia de seu casamento com o herdeiro de uma indústria de louças da cidade. Apesar de ex-aluno de um prestigiado 
colégio católico masculino, ele fizera um uso fraco do sistema de ensino, adquirindo seu diploma superior em uma instituição de ensino superior privada, menos prestigiosa. Quando formada, Alice montou seu primeiro escritório de decoração.

Casada e com dois filhos deu continuidade às suas atividades de trabalho, não o interrompendo em nenhum momento, "se eu pudesse voltar, eu iria um pouco mais devagar". Sua disposição para o trabalho também foi condenada: "Uma Vasconcelos não trabalha fora", estava escrito no bilhete anônimo que recebeu, que ela supôs ter sido enviado pela família do marido. Mas sua posição social sólida e sua experiência educacional, marcada pela aprovação da instituição escolar e da família, lhe permitiram reagir com a segurança de si descrita por outros sociólogos como um traço importante da "cultura burguesa" e que é freqüentemente encontrada entre aqueles acostumados a controlar o julgamento dos outros sobre si (cf. Pinçon e Pinçon-Charlot, 1997; Le Wita, 1988). Maria Alice simplesmente ignorou o fato, prosseguindo em sua empreitada. Um acidente de percurso - a falência material da família do marido - aliado ao sentimento de que era uma menina de alguma forma excepcional permitem compreender porque ela aderiu dessa forma à lógica do trabalho, da concorrência, do dever profissional, recompondo o dever feminino do seu grupo social de acrescentar honras à posição profissional do marido, na figura da mulher "moderna", "empreendedora", "independente". Maria Alice recompôs o dever feminino nesse grupo social por dentro, sem rupturas com o universo familiar, articulando todo o capital simbólico de sua família à sua experiência educacional, para expandir o patrimônio familiar por meio de seu bem-sucedido negócio, uma loja de decoração bem instalada em um endereço chic da cidade, em uma rua conhecida pelo alto valor imobiliário do metro quadrado e pela presença de um comércio de luxo. Daí porque Maria Alice estar situada no quadrante superior esquerdo do Diagrama. Seu caso permite pensar a reprodução simples, caracterizado pela endogamia e acumulação de capitais, mas também a interação deles com os acidentes de percurso ao longo de uma trajetória e os "temas comuns" de um determinado período histórico.

\section{Ana Silvia}

Filha única de um alto funcionário público, ela ingressou na Escola 3 aos 11 anos e permaneceu por lá até terminar o secundário. Vinda de uma 
17.Apenas $2,6 \%$ das brasileiras ocupavam um posto no serviço público no início da década de 1970, período em que Silvia já entrara na vida adulta (Fonte: Fundação Carlos Chagas). família de grandes cafeicultores e dirigentes políticos do interior de São Paulo, mas em declínio financeiro, Ana Silvia articulou não apenas os capitais que herdara de sua família, mas também aqueles que acumulou durante sua longa escolarização. A crise mundial de 1929 levou seus avós à falência e obrigou seu pai a deixar a Faculdade de Direito do Largo de São Francisco para ingressar no serviço público. Sua mãe, egressa de uma outra escola católica da cidade, cursara contabilidade e fazia parte do pequeno contingente feminino que trabalhava no setor público ${ }^{17}$. Como seus avós, antigos dirigentes políticos, e seu pai, que lutara na Revolução Constitucionalista de 1932, Ana Silvia engajou-se cedo em movimentos políticos, militando durante o secundário e dando continuidade à militância no ensino superior. $\mathrm{Na}$ escola era precoce nas leituras, vista como próxima das freiras por suas colegas, embora tenha relatado sua discordância manifestada à época em relação à proibição da leitura de Darwin. Fui recebida, por ela mesma, em seu apartamento, para uma longa entrevista. Quando the indaguei sobre por que fizera Psicologia no Sedes Sapientae e não na USP, ela disse "a Psicologia na USP era mais experimental, behaviorista e eu tinha lido Freud e queria estudar psicanálise”. Esta precocidade intelectual materializada sob a forma tanto da militância estudantil como da clarividência do rumo desejado para sua formação explica o investimento sistemático em sua especialização, resultado do fato de que tinha, já ao final do secundário, um projeto claro de profissionalização. Depois de obter seu diploma superior em Psicologia, decidiu ainda solteira prolongar seus estudos no exterior, beneficiando-se do apoio de sua família, à época temerosa com as represálias do golpe militar de 1968 a estudantes. Conheceu seu futuro marido em uma universidade católica da Europa, um estudante de Filosofia, que possuía uma origem social bem mais modesta do que a sua, tendo sido enviado para lá como seminarista. Ana Silvia e o marido tiveram dois filhos e viveram durante alguns anos na Europa, quando estagiou junto à Françoise Dolto, psicanalista francesa. Como boa parte do grupo pesquisado, ela também se viu em algum momento diante da necessidade de "acompanhar o marido" em função de deslocamentos profissionais dele.

Estava fora de cogitação não acompanhá-los nas mudanças, mas a forma de acompanhá-los também se mostrou variada entre os diferentes grupos de mulheres. Se para as egressas da Escola 2 isso significou sair da cena profissional, parar e cuidar da família, para a maior parte das ex-alunas da Escola 3 esta ocasião foi percebida como a oportunidade de investir em uma especialização profissional ou na necessidade de reconversão na ativi- 
dade profissional. Mas os casos analisados, como o de Ana Silvia, sugerem que se tratava principalmente daquela disposição trabalhada no colégio de responsabilizar-se, de tomar a palavra, ser ativa e "ter projetos", como na expressão de uma outra ex-aluna.

\section{Conclusão}

A principal indagação que esta pesquisa permite elaborar está relacionada com o grau de coincidência entre as propriedades sociais das famílias, o tipo de socialização escolar que as três escolas pesquisadas propiciavam e as trajetórias do grupo pesquisado. Esse encontro, vivido como uma escolha pelas famílias, em um mercado no qual se instalaram escolas para todos os gostos, foi examinado aqui na tentativa de compreender como se estabelecia essa relação de extrema confiança entre as famílias de alta renda e as escolas voltadas para atendê-las. Isso também acontece em países que possuem um sistema de ensino público bem estabelecido, porque os grupos dominantes se concentram em determinados espaços geográficos e criam estratégias, mais ou menos eficazes, para controlar a escola pública que serve ao bairro. No Brasil, entretanto, o peso da escola privada para os grupos intermediários e dominantes reforça ainda mais a possibilidade de que tais estabelecimentos de ensino funcionem de maneira altamente ajustada às expectativas das famílias e contribuam decisivamente para a reprodução dos privilégios. É por esse motivo que as trajetórias se parecem com os colégios, refletindo, em momentos de tomada de decisão, esquemas de pensamentos apreendidos na escola e por meio da experiência de uma dada posição social. Como vimos, a experiência escolar agia como uma instância de socialização em continuidade com as experiências do meio familiar, reforçando-a sempre, sem contrariá-la, sem dispersão. Os dados permitem verificar também como a prática da endogamia passa nesse período a interagir com as qualificações educacionais dos cônjuges, dando provas de como a passagem pelo sistema de ensino e em particular ao ensino superior recompôs os critérios de escolha do cônjuge, trazendo à tona a força do componente escolar até mesmo para as escolhas aparentemente mais livres, como a escolha matrimonial. 


\section{Referências Bibliográficas}

Aguiar, Neuma. (1979), "Mulheres na força de trabalho na América Latina”. Trabalho apresentado no III Encontro Nacional da Anpocs, Caxambu.

Arruda, Maria Arminda do Nascimento. (2001), Metrópole e cultura: São Paulo no meio do século $X X$. Bauru, SP, Edusc.

Barroso, Carmem \& Mello, Guiomar N. de. (1977), "O acesso da mulher ao ensino superior”. Cadernos de Pesquisa, 15: 47-75, São Paulo.

Baudelot, Christian \& Establet, Roger. (1992), Allez les filles. Paris, Seuil.

Berger, Peter \& Luckmann. (1994), A construção social da realidade. Petrópolis, Vozes. Bourdieu, Pierre. (1980), Le sens pratique. Paris, Minuit. . (1989), La noblesse d'état. Paris, Minuit . (1996), As regras da arte. São Paulo, Companhia das Letras. (1999), "Sistemas de ensino e sistemas de pensamento". In: A economia das trocas simbólicas. São Paulo, Perspectiva, pp. 203- 230. . (2000), "L'inconscient d'école". Actes de la Recherche en Sciences Sociales, 135: 3-5, dez., Paris.

Blay, Eva. (1978), Trabalho domesticado. São Paulo, Ática.

Bruschini, Cristina. (1978), "Mulher e trabalho: engenheiras, enfermeiras e professoras". Cadernos de Pesquisa, 27 (1): 3-17, São Paulo.

Carelli, Mário. (1988), Carcamanos e comendadores: os italianos de São Paulo, da realidade à ficção. São Paulo, Ática.

Cookson, Peter \& Persell, Caroline. (1985), Preparing for power. Nova York, Basic. DurKheim, Emile. (1922), Éducation et sociologie. Paris, PUF.

Elias, Norbert. (2000), Os estabelecidos e os outsiders. Rio de Janeiro, Jorge Zahar.

Faguer, Jean-Pierre. (1997a), "Esposa e colaboradora”. In: Bourdieu, Pierre (org.). A miséria do mundo. Petrópolis, Vozes.

. (1997b), “Os efeitos de uma 'educação total': um colégio jesuíta, 1960”. Educação e Sociedade, 58: 9-53.

Fausto, Boris. (1997), Negócios e ócios: histórias da imigração. São Paulo, Cia. das Letras.

Freire, F. H. M. A. et al. (2005), "Dinâmica da nupcialidade: casamento, divórcio, viuvez e re-casamento no Nordeste". Anais do I Encontro sobre Famílias e Políticas Públicas no Brasil. Belo Horizonte, Abep.

Freud, Sigmund. (2006), "Um distúrbio de memória na Acrópole”. In: Obras Completas de Sigmund Freud. Vol. 22: Novas conferências introdutórias sobre psicanálise e outros trabalhos (1932-1936). Rio de Janeiro, Imago, pp. 237-245.

GouveiA, Aparecida Joly. (1968), "Democratização do ensino superior”. Revista Brasileira de Estudos Pedagógicos, 112: 232-244, Brasília. 
Heilborn, M. L. \& Sorj, B. (1999), “Estudos de Gênero no Brasil”. In: Miceli, S. (org.).O que ler na ciência social brasileira (1970-1995). São Paulo, Sumaré, pp. 183-222.

KNiBIEHLER, Yvone. (2001), Maternité, affaire privée, afaire publique. Paris, Bayard.

Lebaron, Frédéric. (1998), La croyance économique. Paris, Seuil.

LE WITA, Béatrix. (1988), Ni vue, ni connue: aproach etnographique de la culture bourgeoise. Paris, Maison des Sciences de l'Homme.

Manoel, Ivan. (1996), Igreja e educação feminina: 1859-1919. São Paulo, Unesp.

Marchetti, Domingos \& Polinésio, Julia M. (1999), Memórias a duas vozes. São Paulo, Annablume.

Miceli, Sergio. (1979), Intelectuais e classe dirigente no Brasil. Rio de Janeiro, Difel. . (1988), A elite eclesiástica brasileira. Rio de Janeiro, Bertrand Brasil.

Morse, Richard. (1970), Formação histórica de São Paulo: de comunidade a metrópole. São Paulo, Difel.

Muel Dreyfus, Francine. (1975), “L'école obligatoire et l'invention de l'enfance anormale". Actes de la Recherche en Sciences Sociales, 1: 60-74, jan., Paris. . (1996), Vichy et l'éternel féminin. Paris, Seuil.

Pastore, José. (1972), O ensino superior em São Paulo. São Paulo, Companhia Editora Nacional/Instituto de Pesquisas Econômicas da Universidade de São Paulo.

Perosa, Graziela. (2005), Três escolas para meninas. Campinas. Tese de Doutorado. Faculdade de Educação da Unicamp.

Pinçon, Michel \& Pinçon-Charlot, Monique. (2003), Sociologie de la bourgeoisie. Paris, La Decouverte. . (1997) Voyage en grande bourgeoisie. Paris, Quadrige/PUF.

Queiroz, Luis Cesar de \& LAGO, Luciana Corrêa. (2000), "O espaço social das grandes metrópoles brasileiras: São Paulo, Rio de Janeiro e Belo Horizonte”. Revista Brasileira de Estudos Urbanos e Regionais (Anpur), 3 (2): 111-129, nov., Recife.

Ringer, Fritz. (2003), "La segmentation des systèmes d'enseignement". Actes de la Recherche en Sciences Sociales, 149: 6-20, set., Paris. . (1979), Education and society in modern Europe. Bloomington/Londres, Indiana University Press.

SAinT-Martin, Monique de. (1990), "Une 'bonne’ éducation: les oiseaux, à Sèvres”. Ethnologie Française, (20): 60-70, Paris.

SAFIOtTI, H. (1981), Do artesanal ao industrial: a exploração da mulher. São Paulo, Hucitec. ScotT, Joan. W. (1990), "L'ouvrière, mot impie, sordide... le discours de l'économie politique française sur les ouvrières (1840-1860)". Actes de la Recherche en Sciences Sociales, 83: 2-15, jun., Paris

ThÉBAud, Françoise. (2001), "Féminisme et maternité: les configurations du siècle" In: KNiBIEHLER, Yvone. (2001). Maternité, affaire privée, afaire publique. Paris, Bayard. 
Trigo, Maria Helena Bueno. (1997), Espaços e tempos vividos: estudo sobre os códigos de sociabilidade e relaçôes de gênero na Faculdade de Filosofia da USP (1934-1970). São Paulo. Tese de Doutorado. FFLCH, USP.

VillaçA, Flávio. (1998), Espaço intra-urbano no Brasil. São Paulo, Fapesp.

Weinstein, Bárbara. (1995), “As mulheres trabalhadoras em São Paulo: de operárias não qualificadas a esposas profissionais". Cadernos Pagu, (4): 143-171.

\section{Resumo}

\section{Educação diferenciada e trajetórias profissionais femininas}

Este artigo tem como objetivo examinar os usos e os efeitos da passagem pelo sistema de ensino, focalizando estratégias desenvolvidas por famílias de dirigentes paulistas para controlar a educação escolar de suas filhas, em uma cidade em acelerado processo de urbanização, crescimento demográfico vertiginoso e de industrialização crescente como era São Paulo nas décadas de 1950 e 1960 . Constituiu em objeto de estudo as trajetórias socioprofissionais de um grupo de mulheres, ex-alunas de três escolas católicas da cidade, para interrogar-se sobre a gênese dos investimentos femininos no mundo social. Os procedimentos de pesquisa incluiram uma pesquisa de campo, a aplicação de questionários e a realização de entrevistas biográficas com ex-professoras, diretoras das escolas e ex-alunas. Os resultados sugerem que o investimento diferenciado dessas mulheres sobre a esfera profissional está relacionado com a estrutura de patrimônio das famílias, as formas de estruturar a experiência escolar das meninas e os padrões de alianças matrimoniais realizadas por esse grupo de mulheres.

Palavras-chave: Famílias de elite; Escola privada; Profissionalização feminina.

Texto recebido e aprovado em 27/3/2008.

Graziela Perosa é professora da Escola de Artes, Ciências e Humanidades (EACH), Universidade de São Paulo.

\section{Abstract}

The effects of educational differences on women's professional careers

This research studied the social and professional experience of a group of 82 women born between 1940 and 1950, coming from high income groups from São Paulo city, all ex-students of three Catholic women's colleges. The main objective was to identify and compare the forms of socialization to which they were exposed in their socioprofessional training. Research methodology included fieldwork, questionnaires and biographical interviews with former lecturers, school directors and past students. The study's findings enabled a better understanding of the mechanisms through which socialization processes determine the different dispositions characterizing the former students of a particular teaching system. They also helped show how the outcomes of this 'primary' socialization interact with later experiences, modifying, reconstituting or reproducing past social patterns and expectations.

Keywords: Elite families; Private school; Women's professionalization. 